American Journal of Applied Sciences 6 (10): 1812-1814, 2009

ISSN 1546-9239

(C) 2009 Science Publications

\title{
Diagnostic Endoscopy in Children of Two Months to 15 Years of Age
}

\author{
Seddiqe Amini-Ranjbar and Mohammad-Hossein Torabinejad \\ Kerman Neuroscience Research Center and Department of Pediatrics, \\ Kerman University of Medical Sciences, Kerman, Iran
}

\begin{abstract}
Problem statement: Considering high prevalence of gastrointestinal complaints in children and the important role of endoscopy in the diagnosis of such complaints, this study was designed to characterize the clinical, endoscopic and pathologic features of Iranian children undergoing upper Gastrointestinal (GI) endoscopy. Approach: This prospective study was performed in an office-based setting in a private medical centre in Kerman, Iran, between December 2004 to January 2008. Three hundred forty pediatric patients who underwent upper endoscopy for dyspeptic symptoms or other reasons were enrolled into this study and data were gathered concerning age, sex, reason of endoscopy, endoscopy report and pathologic report. Upper GI endoscopy was performed using Pentax video endoscope. Results: The most prevalent reason of performing endoscopy (43.1\%) was abdominal pain. More than half of the cases with abdominal pain (54\%) were in the age range of 5-10 year old of whom $80 \%$ had an abnormal pathologic finding such as esophgitis and active chronic gastritis associated with helicobacter pylori. The most common endoscopic finding (31.2\%) and pathologic finding $(40.3 \%)$ was esophagitis. More than half of the children with esophagitis (56.6\%) had some degrees of hiatal hernia. In $35.5 \%$ of children with nodular gastritis, simultaneous esophagitis was observed. The rate of normal endoscopies and pathologies were respectively 10.8 and 19.4\%. Conclusion: Considering low rate of normal endoscopic and pathologic reports in the studied subjects and also the variety of gastrointestinal complaints in them, it seems that proper selection of patients for undergoing upper GI endoscopy can have a significant directive role in the diagnosis of pediatric problems.
\end{abstract}

Key words: Upper GI endoscopy, abdominal pain, pediatrics, Iran

\section{INTRODUCTION}

Gastrointestinal diseases such as chronic abdominal pain, vomiting and diarrhea are common all around the world ${ }^{[1]}$. Finding causes of gastrointestinal problems leads to more efficient treatment and consequently decreases morbidity and mortality rates ${ }^{[2]}$

Endoscopy is the best method for the diagnosis of most of these disease and its application in children is increasing $^{[3-5]}$. Endoscopy, in addition to being a valid diagnostic technique, in many cases can be used as a therapeutic method as well. For example, esophgitis, erosive gastritis, Mallory-Wiess syndrome and upper GI bleedings can be treated by endoscopy ${ }^{[4,6]}$.

In addition to the high sensitivity of endoscopy in the diagnosis of diseases, lack of radiation is the other important advantage of endoscopy ${ }^{[6]}$. Because of lack of information about the prevalence rate of some gastrointestinal diseases in children such as helicobacter pylori or esophagitis ${ }^{[3,7]}$ high rate of endoscopic studies in adults and recently increasing rate of endoscopy for the diagnosis of pediatric diseases ${ }^{[8]}$ and the variety of gastrointestinal complaints in different ages and different areas ${ }^{[6-8]}$, the present study was designed to characterize the clinical, endoscopic and pathologic features of Iranian children undergoing upper Gastrointestinal (GI) endoscopy in comparison to children in other countries.

\section{MATERIALS AND METHODS}

This prospective study was performed in an officebased setting in a private medical centre in Kerman, Iran, between December 2004 to January 2008. Three hundred forty pediatric patients who underwent upper endoscopy for dyspeptic symptoms or other reasons were enrolled into this study and data were gathered concerning age, sex, reason of endoscopy, endoscopy report and pathologic report.

Upper GI endoscopy was performed using Pentax video endoscope. Intravenous midazolam or rectal diazepam were administered as tranquilizer if required.

Corresponding Author: Seddiqe Amini-Ranjbar, Kerman Neuroscience Research Center, Kerman University of Medical Sciences, Kerman, Iran Tel/Fax: +983412663815 
From all children, 5 biopsy samples ( 2 from esophagus and 3 from stomach) had been taken and Urease test had been performed too. Moreover duodenum biopsy had also been performed in cases such as obvious abnormal finding in duodenum, abdominal distension, anemia, chronic diarrhea, low weight, anorexia, rectal prolapse and generalized edema. Those cases with esophageal varices did not undergo biopsy. All children whose pathological reports were ambiguous or did not have the pathological report due to insufficient samples were excluded from the study. Informed consent was obtained from their parents.

For statistical analysis, children were divided into three age group of <4 years, 5-10 years and >10 years. Data analysis was conducted using SPSS V.16.

\section{RESULTS}

Result: The studied children were at the age of 2 months to 15 years. Most of them $(83.5 \%, \mathrm{n}=284)$ were below 10 years of whom 145 ones $(42.6 \%)$ were below 4 years. From 340 studied children, 168 ones $(49.5 \%)$ were male and 172 ones $(50.5 \%)$ were female. Abdominal pain $(43.1 \%)$ and vomiting $(23 \%)$ were the most common causes of undergoing upper GI endoscopy (Table 1).

Table 1: Indications of upper endoscopy in 2 months 15 years old Iranian children

\begin{tabular}{lcc}
\hline Indication & Number & Percent \\
\hline Abdominal pain & 147 & 43.1 \\
Nausea/vomiting & 78 & 23.0 \\
Failure to thrive & 27 & 8.0 \\
Hepatosplenomegaly & 24 & 7.0 \\
Chronic diarrhea & 17 & 5.0 \\
Gastrointestinal bleeding & 14 & 4.0 \\
Heart burn & 9 & 2.5 \\
Dysphagia & 5 & 1.4 \\
Others & 19 & 6.0 \\
\hline Total & 340 & 100.0 \\
\hline
\end{tabular}

Table 2: Endoscopic findings in 2 months 15 years old Iranian children

\begin{tabular}{lcc}
\hline Indication & Number & Percent \\
\hline Esophagitis & 106 & 31.2 \\
Nodular gastritis & 79 & 23.3 \\
Hiatal hernia & 68 & 20.0 \\
Normal & 37 & 10.8 \\
Esophageal varices & 23 & 6.7 \\
Others & 27 & 8.0 \\
\hline Total & 340 & 100.0 \\
\hline
\end{tabular}

Table 3: Pathological findings in 2 months- 15 years old Iranian children

\begin{tabular}{lcc}
\hline Indication & Number & Percent \\
\hline Esophagitis & 137 & 40.3 \\
Normal & 66 & 19.4 \\
Chronic active gastritis & 52 & 15.3 \\
Esophagitis + gastritis & 19 & 5.6 \\
Chronic duodenitis & 15 & 4.4 \\
Celiac disease & 11 & 3.3 \\
Others & 17 & 5.0 \\
Not exam (varices) & 23 & 6.7 \\
\hline
\end{tabular}

More than half of the cases with abdominal pain $(54 \%$, $\mathrm{n}=79$ ) were in the age range of 5-10 years of whom, $80 \%$ had an abnormal finding such as esophagitis, chronic gastritis or active chronic gastritis associated with helicobacter pylori or chronic duodenitis in their biopsies. Most of the cases with vomiting $(61.5 \%$, $\mathrm{n}=48$ ) were in the age group of $<4$ years of whom, $79 \%$ had esophgitis.

Esophagitis was the most prevalent finding reported in endoscopy (31.2\%) and pathologic (40.3\%) findings (Table 2 and 3). In more than half $(56.6 \%$, $n=60)$ of the children who had esophgitis based on their endoscopy, some degrees of hiatal hernia were observed. Esophagitis was seen in 28 children $(35.5 \%)$ with nodular gastritis simultaneously.

\section{DISCUSSION}

Considering the high prevalence of gastrointestinal complaints and increasing rate of diagnostic endoscopy in children and also lack of sufficient knowledge about the endoscopic findings in children of our region, in current study 340 upper GI endoscopies performed on pediatric patients in order to find the etiology of common gastrointestinal complaints.

Abdominal pain was the most prevalent (43.1\%) indication of upper GI endoscopy and its rate was higher in comparison to the studies in Saudi Arabia (24\%) (5) and Ordon (24\%) (9), but similar to the study in Ghana $(42.5 \%)^{[6]}$ and lower in comparison to the reported value in Uganda study $(67.4 \%)^{[3]}$.

The most prevalent endoscopic finding in the present study was esophagitis that is very different with Uganda and Kenya studies in which respectively duodenum ulcer $(14.8 \%)$ and gastritis $(25.8 \%)$ had been the most prevalent abnormal finding ${ }^{[3,10]}$.

The prevalence rate of hiatal hernia in Iranian children $(20 \%)$ was also significantly higher than that in Ghana $(0.8 \%)^{[6]}$ and Ordon $(3.6 \%, \mathrm{n}=2$ from 168 cases $)^{[9]}$.

The significant difference in the rate of normal endoscopic reports between the present study (10.8\%) and Uganda (51\%), Ghana (41.1\%) and Kuwait (32\%) studies $^{[3,6,11]}$ all may be the result of difference of the present study and the mentioned studies in regard to the age range and race of the studied patients, geographical conditions, nutritional and health habits and criteria for selecting patients for endoscopy ${ }^{[3]}$.

The most prevalent pathological finding in the current study was esophagitis $(40.3 \%, \mathrm{n}=137)$, while in Ordon study celiac had been the most common histological finding and esophagitis had been the third prevalent finding ${ }^{[9]}$. The prevalence rate of esophagitis 
in our study had significant difference with that in Ghana $(7.5 \%)(6)$ and Singapore $(4.3 \%)^{[12]}$, Kuwait $(7 \%)^{[11]}$, although it is closer to the value found in Saudi Arabia study $(30 \%)^{[5]}$, the differences may be due to the methods of selecting patients.

Esophagitis as the most prevalent endoscopic $(31.2 \%)$ and histological finding $(40.3 \%)$ in the present study may be evident of the high incidence of this disease among children with gastrointestinal complaints, especially abdominal pain and vomiting in the current study. Therefore in facing these kinds of complaints in children the clinician should think to esophagitis in order to avoid serious complications such as esophageal stenosis. In the present study, at least 3 cases of esophageal stenosis due to reflux were observed. Since in most cases $(61.5 \%)$ vomiting was seen in children less than 4 years of age and in $79 \%$ of the cases it was associated with esophagitis, it can be concluded that the high prevalence of esophagitis in this study has been due to the following reasons: first, this problem may be due to physiologic reflux that sometimes continues even till the age of 4 years and second, the high incidence of hiatal hernia among children with esophagitis in this study might act as an underlying factor for the occurrence of esophagitis. In order to achieve better conclusion in this regard, follow up of patients and repeated endoscopies would be beneficial.

Low rate of normal endoscopic reports (10.8\%) and pathological reports $(19.4 \%)$ in the current study may be because of proper selection of patients for endoscopy, several sampling from proper places or high attention of pathologist in studying samples.

The mentioned differences and similarities of indications of endoscopy and endoscopic and pathological findings between the present study and other studies may be evident of different prevalence rates of diseases in children who had similar complaints. With proper selection of patients for endoscopy, it can be used more efficiently in the diagnosis of these diseases.

\section{CONCLUSION}

Considering low rate of normal endoscopic and pathologic reports in the studied subjects and also the variety of gastrointestinal complaints in them, it seems that proper selection of patients for undergoing upper GI endoscopy can have a significant directive role in the diagnosis of pediatric problems.

\section{REFERENCES}

1. El-Mouzan, M.I., A.M. Abdullah, A.M. Al-Sanie and S.I. Al-Khalifah, 2001. Pattern of gastroesophageal reflux in children. Saudi Med. J., 22:419-22. PMID: 11376384
2. Agbakwuru, E.A., A.O. Fatusi, D.A. Ndubula, O.I. Alatise, O.A. Arigbabu and D.O. Akinola, 2006. Pattern and validity of clinical diagnosis of upper gastrointestinal disease in south-west Nigeria. Afr. Health Sci., 6: 98-102. PMID: 16916300

3. Okello, T.R., 2006. Upper gastrointestinal endoscopic findings in adolescents at Lacor hospital, Uganda. Afr. Health. Sci., 6: 39-42. PMID: 16615826

4. Walker, W.A., O. Goulet, R.E. Kleinman, P.M. Sherman, B.L. Schneider and I.R. Sanderson, 2004. Pediatric Gastrointestinal Disease, Pathophysiology, Diagnosis, Management. 4th Edn., BC Decker, Hamilton, ISBN: 1550091298, pp: 388-394.

5. El-Mouzan, M.I., I.A. Al-Mofleh, A.M. Abdullah and R.S. Al-Rashed, 2004. Indications and yield of upper gastrointestinal endoscopy in children. Saudi Med. J., 25: 1223-5. PMID: 15448770

6. Aduful, H.K., S.B. Aeder, R. Darko, B.N. Baako, J.N.A. Clegg-Lamptey and K.N. Nkrumah, 2007. Upper gastrointestinal endoscopy at the Korle $\mathrm{Bu}$ Teaching hospital, Accra, Ghana. Ghana Med. J., 41: 12-15. PMID: 17622333

7. El-Mouzan, M.I., I.A. AL-Moflet and A.M. Abdullah, 2005. Gastritis in Saudi Arab children. Saudi Med. J., 26: 576-9. PMID: 15900363

8. Kochhar, R., V.K. Misra and S.S. Tambi, 1989. Upper gastrointestinal endoscopy in infants and children. Indian Pediatr., 26: 129-33. PMID: 2787786

9. Rawashdeh, M.O., N. Abu-Farsakh and T.M. AL-Jabr, 1996. Paediatric upper gastrointestinal endoscopy in developing countries. Ann. Trop. Paediatr., 16: 341-6. PMID: 8985532

10. Lodenyo, H., F. Rana, G.Z. Mutama, J.K. Kuria and F.A. Okoth, 2005. Patterns of upper gastrointestinal disease based on endoscopy in the period 1998-2001. Afr. J. Health. Sci., 12: 49-54. PMID: 17298139

11. Abahussain, E.A., F.A. Hasan and P.J. Nicholls, 1998. Dyspepsia and helicobacter Pylori infection: Analysis of 200 Kuwaiti patients referred for endoscopy. Ann. Saudi Med., 18: 502-505. PMID: 17344719

12. Quak, S.H., S.K. Lam and P.S. Low, 1999. Upper gastrointestinal endoscopy in children. Singapore Med. J., 31: 123-6. PMID: 2371574 